\title{
Los derivados crediticios de tercera generación y su relación con la crisis hipotecaria del mercado subprime en Estados Unidos
}

\author{
Eduard Berenguer \\ Departament de Teoria Econòmica \\ Universitat de Barcelona
}

\begin{abstract}
RESUMEN
Este artículo analiza el papel de los derivados crediticios de tercera generación y su relación en la crisis del mercado subprime. Aunque los medios de comunicación han interpretado los CDO como un caso de alquimia fallida, nuestra visión es que las causas de la crisis del mercado subprime deben de atribuirse más a un error en la fijación del precio del riesgo motivado por la mala calidad del subyacente y la creencia de que el precio de las viviendas iba acontinuar subiendo que por la propia naturaleza de los productos estructurados.
\end{abstract}

* Sin implicarlos en el contenido y las opiniones emitidas, agradezco a Joan Hortalà, Oscar Mascarilla y Jesús M. García Iglesias los comentarios y sugerencias aportados a una primera versión de este trabajo. . 


\section{INTRODUCCIÓN}

Este trabajo tiene por objeto describir la naturaleza y propiedades de los derivados crediticios y, en especial, de los CDS (credit default swaps) y los CDOs (collateralized debt obligations) así como la relación de estos últimos con la crisis hipotecaria del llamado mercado hipotecario subprime de Estados Unidos. Estos derivados han experimentado una gran expansión en la última década, gracias a su capacidad para transferir riesgos y proporcionar liquidez a los mercados crediticios. Aunque no hay estadísticas precisas, y el valor de los contratos nominales en circulación depende de la fuente consultada, todas ellas parecen estar de acuerdo que el volumen de los derivados crediticios ha pasado de menos de 100.000 millones de dólares a mediados de la década de los 90 a aproximarse al billón de dólares en el año 2001. A partir de esta fecha el crecimiento ha sido espectacular: 2 billones de dólares en el 2003, 4 billones de dólares en el 2004 y 26 billones de dólares a finales del 2006. De esta última cifra, 1 billón estaría representado por $\mathrm{CDOs}^{1}$.

Se denominan de tercera generación, para distinguirlos de sus antecesores de primera generación (opciones de compra (calls) y venta (puts) sobre acciones) y de los de segunda generación (derivados sobre renta fija). La adscripción a una nueva generación se debe, en este caso, al hecho de que todos estos derivados tienen en común la posibilidad de recomponer los flujos de caja que proporciona algún tipo de activo subyacente y ofrecer flujos de caja alternativos que no sería posible obtener de acuerdo con los activos financieros existentes en el mercado. Esta descomposición permite la transferencia de riesgos en una forma que no era posible hasta su aparición. Por ejemplo, en el caso de los CDS este derivado permite a un banco aislar al crédito como una clase de activo y riesgo con entidad propia diferenciada de otros activos parecidos $^{2}$. Los CDO y otros productos financieros estructurados creados a su alre-

${ }^{1}$ Las fuentes utilizadas para estas estadísticas son: British Bankers' Association, Biannual Survey, hasta 2002. Fitch Ratings, «Global Credit Derivatives: Risk Management or Risk?» Fitch Ratings Credit Policy Special Report, 2003. Laurie S. Goodman, Douglas J. Lucas, and Frank J. Fabozzi, «Financial Innovations and the Shaping of Capital Markets: The Case of CDO's», The Journal of Alternative Investments, Verano 2007 y Tim Weithers, «Credit Derivatives, Macro Risks, and Systemic Risks», Documento de trabajo de la Universidad de Chicago, abril de 2007.

${ }^{2}$ De acuerdo con Choudhry un crédito bancario tiene tres tipos distintos de riesgos: el ries- 
dedor representan un paso adicional en el proceso de titulización cuyo mayor beneficio consiste en que permite descomponer un riesgo determinado en otros adaptados a distintos inversores con grados diferentes de aversión al riesgo.

Aunque sólo sea por la importancia de su volumen, los efectos que han tenido estos instrumentos de tercera generación sobre los mercados financieros han sido muy importantes. Por una parte, las empresas y gobiernos han encontrado la oportunidad de emitir deuda en unos términos que les resultan más atractivos que los ofrecidos por los intermediarios financieros clásicos, incluido en el caso de las empresas el recurso a las ampliaciones de capital en las bolsas de valores ${ }^{3}$. Por otra parte, el crecimiento en las emisiones de deuda ha dado lugar a todo un conjunto de nuevos instrumentos en la medida que los bancos han encontrado alternativas a la actividad crediticia tradicional, en la que la oferta de crédito dependía del volumen de pasivo captado y los créditos concedidos figuraban en sus libros de contabilidad hasta su extinción. La banca actual en muchos casos se ha convertido simplemente en el originador y distribuidor de los créditos, actuando como intermediaria entre los solicitantes y los mercados de capitales que son los que se quedan finalmente con ellos. En otros casos, el valor de los créditos no ha desaparecido de los libros de contabilidad de los bancos, aunque su riesgo ha sido transferido a inversores que a cambio de unas primas relativamente modestas han optado por asegurar los créditos que aquellos habían concedido. En uno y otro caso, los bancos han podido operar con volúmenes de capital menores que los que habrían sido necesarios sin la existencia de estos derivados y centrar su actividad en la rentabilización de este capital (creación de valor para los accionistas).

El cambio en el papel de los bancos y la facilidad para transferir riesgos, sin embargo, puede plantear problemas importantes de riesgo moral en la medida que puede afectar a la operativa tradicional de concesión de créditos y dar lugar a normas

go crediticio, el riesgo de mercado y el riesgo de financiación. Los derivados crediticios permiten separar el riesgo crediticio del de mercado y el de financiación. Ver Moorad Choudhry, «The Credit Risk Sling», GARP Risk Review, enero/febrero 2003, pág. 10.

${ }^{3}$ El teorema de Modigliani y Miller indica que para valorar la rentabilidad de una empresa es indiferente la composición de su estructura de capital entre capital propio y deuda. Jensen rebatió este argumento, al señalar que la emisión de deuda generaba un compromiso que obligaba a los gerentes a buscar proyectos de inversión que permitieran el pago de la deuda y de sus intereses, de modo que la probabilidad de que estos proyectos fueran más rentables que los que se seleccionan invirtiendo las reservas (fondos propios) era muy alta. 
más laxas en su concesión, que debe interpretarse en el sentido que del total de los créditos concedidos ahora existe una probabilidad positiva de que aumente el porcentaje de créditos que acaban siendo insolventes. Aunque la existencia de efectos reputacionales puede moderar los incentivos a suavizar los numerosos requisitos presentes en la concesión de créditos, no hay que pasar por alto que el desarrollo experimentado por los mercados financieros ha permitido la entrada de nuevos operadores con menor experiencia y sin una reputación previa que defender, sin estar sujetos a la supervisión de los bancos centrales que han actuado con el único objetivo de maximizar el volumen de crédito originado. En un sentido bastante preciso, estos operadores podrían ser considerados como simples «buscadores de rentas» con las connotaciones y efectos que eso conlleva.

El proceso de crecimiento de los derivados de tercera generación que, sobre el papel, permite que los mercados financieros alcancen de forma más eficiente su papel como intermediarios entre los oferentes y demandantes de capital, sin embargo, ha tenido lugar en unas condiciones económicas muy peculiares, caracterizado por una fase de crecimiento sostenida, baja inflación y bajos tipos de interés. Aunque crisis financieras de distinto tenor no han estado exentas, normalmente éstas han sido superadas rápidamente. No obstante, cabe constatar como ya indicaba Joseph Cilia ${ }^{4}$ en 1996, que los períodos en los que los tipos de interés son muy bajos dan lugar a una demanda extraordinaria de títulos que ofrezcan rentabilidades atractivas por encima de los denominados activos libres de riesgo. Aunque las bolsas de valores acostumbran a tener un buen comportamiento durante estas fases, hay, sin embargo, una corriente que opina que el rendimiento de las acciones es pequeño en comparación a los riesgos que comportan por lo que prefieren invertir en los llamados bonos de alto rendimiento o en otros tipos de activos financieros con mayor riesgo. Ahora bien, si en una situación de abundante liquidez, aumenta la demanda de activos con riesgo, el efecto final es que el diferencial de estos activos respecto a los activos libres de riesgo tiende a disminuir. Esto fuerza a buscar aún activos con mayor riesgo y a ampliar la oferta de derivados destinados a recomponer los flujos de caja proporcionados por los activos subyacentes.

Ahora bien, toda recomposición de los flujos de caja implica que en algún lugar, junto a la promesa de un mayor rendimiento se ha producido un incremento del ries-

${ }^{4}$ Cilia, Joseph, «Asset Swaps: Creating Synthetic Instruments», Federal Reserve Bank of Chicago, 1996. 
go. Este incremento, puede además multiplicarse extraordinariamente en la medida que los inversores adquieran los nuevos activos desde posiciones apalancadas. En una situación adversa, el inversor que se ha apalancado puede encontrarse no sólo con que ha perdido el importe de su inversión, sino que además ha contraído unas deudas adicionales. A nivel de sistema, pérdidas relativamente modestas en origen pueden multiplicarse enormemente en el otro extremo de los mercados financieros.

En la medida que el valor de los productos derivados depende en parte de la fase del ciclo económico en que se negocian hay que suponer que para quienes los adquieren incluyen riesgos que se corresponden al llamado «riesgo de mercado». La experiencia reciente seguramente sugiere que estos riesgos no siempre han sido tenidos en cuenta y que a la hora de poner precio a estos derivados se han utilizado indicadores (probabilidades de insolvencia y valores de recuperación) cuyo valor en un momento determinado no era representativo del valor que podría alcanzar en un momento posterior, dando lugar a una formación de precios incorrecta. Cuando esto sucede, los beneficios para emisores e inversores en estos derivados quedan alterados.

En los cinco últimos años ha podido observarse una fase de apetito creciente por el riesgo sustentada en la facilidad con que los riesgos han sido transferidos de un extremo a otro del sistema financiero internacional. En algunas partes, se ha hablado de «burbuja crediticia» que quedaría evidenciada en algunos países tanto por el importante crecimiento del crédito bancario en relación al PIB nominal como por la evolución de las ratios deuda/PIB de los diversos actores económicos. En este proceso de crecimiento de los niveles de endeudamiento han participado tanto las familias como los denominados fondos de capital riesgo que han conseguido créditos puente y posteriores emisiones de obligaciones para adquirir determinadas empresas.

El elevado endeudamiento de las familias en los mercados hipotecarios, asociado a un aumento en el porcentaje de familias propietarias y a fuertes crecimientos de los precios de la vivienda, y de los fondos de capital riesgo dispuestos a pagar cada vez sumas mayores por adquirir determinadas empresas, junto al aumento paulatino de los tipos de interés y el anuncio de políticas monetarias menos acomodaticias, ha planeado sobre los mercados financieros desde mediados de 2006.

Sin embargo, el elemento que ha hecho estallar la burbuja en 2007 ha sido un segmento relativamente desconocido del sistema financiero como es el mercado de las hipotecas subprime. Estas son hipotecas concedidas a familias de bajos ingresos sin respetar las reglas tradicionales basadas en el credit scoring y con unas condiciones poco habituales de pago de intereses y devolución del principal que pueden dar lugar a más de un episodio de ilusión financiera. Ahora bien, vale la pena indicar que el famoso efecto riqueza asociado con el aumento del precio de las viviendas no es más 
que una opción call obtenida a título gratuito debido a la tendencia del mercado. Puesto que esta opción tiene un precio positivo no es cuestión de desprenderse de ella de forma gratuita. Por ello, a pesar de que una hipoteca subprime sea un instrumento de alto riesgo con una probabilidad de insolvencia muy alta, ésta difícilmente se materializará mientras el precio del activo se siga revalorizando. Por ello, en el transcurso de una burbuja crediticia, difícilmente el riesgo asociado con estos créditos se hará visible si se atiende únicamente a consideraciones de corto plazo y no se es capaz de prever a largo plazo. En el momento que el nivel de precios deja de subir, la última oleada de consumidores que ha adquirido una vivienda deja de percibir el call y si el mercado invierte esta tendencia entonces al suscribir una hipoteca, los deudores pueden al mismo tiempo estar emitiendo opciones put por las que no cobrarán ninguna prima y que serán ejercidas en el caso de que se tuviera que vender el activo vivienda para cancelar una hipoteca de mayor importe. En estas circunstancias es preferible declararse insolvente antes que pagar el valor del put a la entidad financiera que concedió la hipoteca.

En cualquier proceso en el que el precio relativo de un bien sube mucho en relación al de otros bienes, la actividad especuladora estará normalmente presente así como los buscadores de rentas fáciles. Por ello, no es extraño de acuerdo con la evolución de los precios de la vivienda que el mercado subprime ganara tamaño. Es bastante más sorprendente la facilidad con que todos estos créditos hipotecarios fueron transmitidos y adquiridos por los llamados bancos de inversión y desde aquí a través de un proceso de titulización por medio de CDO y otros vehículos especiales vendidos a otros bancos, fondos de cobertura, fondos de pensiones e inversores en general.

La crisis del mercado subprime evidenciada en 2007 gracias a un aumento muy considerable del porcentaje de insolvencias y sus efectos sobre bancos y fondos de cobertura provocaron el 9 de agosto un desajuste importante en el mercado interbancario (primer eslabón del mecanismo de transmisión de la política monetaria) obligando a los principales bancos centrales a inyectar liquidez de forma apresurada. Los efectos de esta crisis, apoyada en la desconfianza de unas instituciones hacia otras, gracias al desconocimiento de la exposición de cada una de ellas ha afectado de forma importante a los derivados crediticios y en especial a los CDO, pues éstos han sido los vehículos que han recogido las mayores titulizaciones del mercado subprime.

En el resto de este trabajo queremos examinar el papel de los derivados crediticios dentro del sistema financiero. Nuestra conclusión es que, en general, se ha sobrevalorado la capacidad de los CDO para generar valor añadido a los inversionistas, especialmente en lo que se refiere a los llamados CDO de arbitraje cuya selección de 
activos se hace sobre la base de que los activos que se adquieren tienen un valor superior al que les da el mercado. La experiencia del mercado subprime desmiente esta afirmación y es posible que lo ocurrido con las hipotecas del subprime pueda producirse con otro tipo de hipotecas u obligaciones emitidas por empresas de capital riesgo. Junto a ello, debería evitarse confundir el instrumento con su contenido. Si los activos subyacentes que forman la cartera de un CDO tienen calidad y ofrecen un diferencial adecuado respecto a los activos seguros, entonces hay que reconocer que estos derivados tienen un valor indudable tanto por lo que representan para las posibilidades de diversificar y adaptar los riesgos a los gustos de determinados inversores como su efecto nada despreciable de «completar mercados» en el sentido de abrir las puertas de determinados mercados a inversores que por razones legales u de otro tipo no tenían antes acceso a los mismos.

En la siguiente sección (sección II) desarrollaremos brevemente el proceso de transferencia de riesgos crediticios, la aparición de los derivados crediticios en este proceso de transferencia así como las valoraciones que han merecido estos derivados desde distintos puntos de vista. No hay que olvidar en ningún momento que los derivados en general siempre suscitan adhesiones fervientes o críticas desaforadas, por lo que es difícil encontrar juicios ponderados sobre los mismos. En la sección III mostramos como operan los CDS, concentrándonos en la sección IV en la exposición y análisis de los CDO, así como sus distintos tipos. La sección V presenta una primera aproximación a la crisis del mercado subprime en los Estados Unidos. Para ello, recogemos cierta evidencia empírica sobre el comportamiento de los precios de la vivienda y porcentaje de insolvencias para indicar como el porcentaje de insolvencias que pueda darse en un momento determinado en el que los precios suben a tasas de dos dígitos no es un indicador adecuado del riesgo que se asume y se transfiere posteriormente. Salvo que queramos pensar en comportamientos delictivos generalizados, cabe pensar que los mercados han analizado de forma incorrecta el riesgo aunque se disponían de herramientas para evitar algunos de los errores cometidos. Finalmente, la sección VI presenta algunos argumentos sobre precio de la vivienda y mercados hipotecarios que pueden ser relevantes para España, donde sin que pueda ser aplicable todo lo sucedido en Estados Unidos, presenta algunos paralelismos interesantes y plantea algunos interrogantes respecto a cómo se comportará el precio de la vivienda en el futuro. 


\section{LOS DERIVADOS CREDITICIOS: ORIGEN Y EXTENSIÓN}

La actividad crediticia comporta riesgos. El riesgo más evidente es que quien consigue un crédito no lo devuelva, pero éste no es el único riesgo. En los créditos a tipos de interés fijos también existen riesgos asociados con los movimientos del tipo de interés. No es extraño, pues, que los prestamistas hayan siempre que han podido diluir o transferir ese riesgo. En los créditos bancarios, la concesión a tipos de interés variables reduce el riesgo asociado con las subidas del tipo de interés; la exigencia de garantías reales y/o avales reduce el riesgo de pérdidas en caso de no devolución del crédito. La sindicación de los créditos bancarios, concedidos a las grandes empresas, ha sido otra forma tradicional de reducción del riesgo. Finalmente, la existencia de los que podríamos llamar mercados de segunda mano, mediante los cuales el crédito que figura en el activo del balance de un banco es vendido a otra actividad implica una transferencia del riesgo desde la actividad vendedora a la compradora.

Mercados de segunda mano para el crédito bancario han existido desde hace mucho tiempo, pero el hecho de que el banco vendedor tuviera que comunicar a su cliente que su crédito pasaba a ser propiedad de otra entidad era un palo puesto en la rueda de estos mercados. Con la transferencia del crédito, el cliente podía transferir sus cuentas y futuras operaciones a la otra entidad. Por eso los mercados de segunda mano nunca tuvieron un desarrollo apreciable.

La sindicación de los créditos bancarios vino a alterar un poco este panorama, especialmente en los llamados créditos sindicados participados que eliminaron la obligatoriedad de notificar al prestatario la venta de los créditos en los mercados de segunda mano, preparando el terreno para la titulización.

La titulización utilizada en primer lugar para créditos hipotecarios y más tarde para todo tipo de préstamos es una forma interesante de transferencia de riesgo muy utilizada. En un proceso de titulización una entidad financiera reúne todo un conjunto de créditos (hipotecarios o no) que están en su balance y los vende a una entidad creada al efecto. Esta entidad emite obligaciones con las que financia la adquisición de los créditos. Los rendimientos obtenidos de los créditos permiten pagar intereses y parte del principal a los obligacionistas. Aunque la entidad financiera que ha vendido los créditos retiene parte del riesgo de insolvencia de los mismos, pues lo habitual es que el banco que ha vendido los créditos asume las insolvencias que se producen en los cuatro primeros meses, con la titulización 
se produce una amplia transferencia de riesgo a terceros, que de este modo pasan a tener una exposición sintética a la cartera de créditos de la entidad financiera que los originó. En otros casos, es el emisor de las obligaciones el que garantiza el pago de lo comprometido, en cuyo caso cobra al inversor una pequeña prima de aseguramiento.

Un desarrollo interesante en el proceso de titulización (que podría considerarse un precedente de los CDO aunque no debería confundirse con ellos) consiste en las llamadas collateralized mortgatge obligations (CMO) creadas en 1983 para evitar los problemas asociados con el pago anticipado de las hipotecas. Esto constituye un riesgo en la medida en que quien adquiere títulos respaldados por hipotecas puede encontrase con un activo que tiene una vida menor que la que el inversor ha previsto para mantenerlo en su cartera. Las CMO son obligaciones respaldadas por un conjunto de hipotecas pero divididas en distintas clases, estando asociada cada clase a un tipo distinto de vencimiento. Todos los intereses proporcionados por las hipotecas se reparten proporcionalmente entre los obligacionistas, pero el retorno del capital se hace de tal forma que primero se reparte el capital a aquellos inversores que han elegido un tipo de obligación que tiene un vencimiento más corto y así sucesivamente.

Junto a la titulización, los mercados financieros han instrumentado otras alternativas para transferir riesgos. El derivado más importante en los mercados de transferencias de riesgos crediticios son los denominados credit default swaps (CDS). Un CDS es un contrato por medio del cual a cambio de un porcentaje sobre el valor nominal del crédito y la obtención de determinadas garantías en su caso, alguien se compromete a pagar al banco el importe del crédito en caso de impago. Es un contrato derivado porque el beneficio que obtiene el agente que ha vendido protección al banco en relación a ese crédito depende de la evolución del crédito y del valor de las garantías pactadas en caso de impago. Para el banco, en el caso de que su cliente cumpla religiosamente con sus obligaciones, el pago de la protección ofrecida por el CDS le ha servido para dar cobertura al riesgo que estaba asociado con el crédito.

Alan Greenspan, antiguo presidente de la Reserva Federal de los Estados Unidos, en una conferencia dada en el Federal Reserve Bank of Chicago el año 2005, explicó como los derivados crediticios habían actuado para impedir que las consecuencias de las quiebras de Enron y WorldCom en 2001 y 2002 afectaran al sistema bancario. Sencillamente, los bancos que habían prestado dinero a estas dos grandes empresas habían cubierto su exposición al riesgo en el mercado de los derivados crediticios. De este modo, las quiebras de estas empresas no tuvieron efecto alguno en el sector ban- 
cario que pudo continuar con su actividad habitual ${ }^{5}$. No obstante, un mes más tarde, en una conferencia realizada bajo el patrocinio del FMI en Beijing, ya advirtió que algunos fondos de cobertura estaban asumiendo riesgos sin la debida compensación y que los rendimientos de los CDO estaban condenados a resultar decepcionantes en un plazo de tiempo no muy largo. No obstante, no veía en esto un peligro siempre y cuando los bancos y otros prestamistas gestionaran los riesgos crediticios de forma adecuada.

En el año 2005, el Banco Internacional de Pagos encargó al Joint Forum's Working Group on Risk Assessment and Capital un informe sobre la transferencia de riesgos crediticios. En este informe ${ }^{6}$, además de poner de relieve las innovaciones de producto y el aumento del número de participantes y de los volúmenes de las transacciones se llega a la conclusión de «que el continuo desarrollo del mercado para la transferencia de riesgos crediticios ofrece beneficios potenciales en forma de unos mercados más líquidos y eficientes para la transferencia de riesgos crediticios», señalando que los problemas más importantes están relacionados con «la necesidad de que los participantes en el mercado continúen mejorando las técnicas para la gestión del riesgo y para los supervisores y reguladores que continúen mejorando su comprensión de los problemas asociados [con estos instrumentos]» ${ }^{7}$.

El Banco Central Europeo ${ }^{8}$ también ha examinado estos derivados observando que los riesgos estaban más concentrados y correlacionados que en otras clases de

${ }^{5}$ Alan Greenspan, Risk transfer and Financial Stability, Remarks to the Federal Reserve Bank of Chicago's Forty-First Annual Conference on Bank Structure, 5 de mayo de 2005.

${ }^{6}$ The Joint Forum, Credit Risk Transfer. Bank for International Settlements, marzo de 2005.

${ }^{7}$ Un documento anterior del mismo BIS, sin embargo, era más precavido y advertía que los riesgos asociados con determinados productos estructurados como los CDO podían no haber sido asimilados correctamente por parte de determinados inversores. En concreto, el documento advertía que: «El uso de instrumentos financieros estructurados, junto con la posibilidad de que puedan darse los peores escenarios en relación a exposiciones cuyos precios han sido mal calculados o gestionados, podrían dar lugar a situaciones en las que acontecimientos de mercado extremos podrían tener consecuencias sistémicas no anticipadas», BIS, Committee on the Global Financial System, Incentive Structures in Institutional Asset Management and their Implications for Financial Markets», BIS, marzo de 2003.

${ }^{8}$ ECB, «Credit Risk Transfer by EU Banks: Activity Risk and Risk Management», European Central Bank, mayo 2004. 
derivados. A pesar de ello, concluyó su estudio afirmando que «la valoración global de las tendencias en estos mercados es positiva. Las mejoras en las posibilidades de los bancos y otras instituciones financieras para diversificar y cubrir sus riesgos están contribuyendo a que el sistema financiero se haga más eficiente y estable».

M. Gibson ${ }^{9}$ considera que los beneficios más importantes que se pueden obtener de la existencia de estos derivados crediticios es que permiten a los inversores obtener una relación riesgo/rendimiento deseada a un coste mucho menor que si éstos tuvieran que buscar uno a uno en el mercado todos los activos subyacentes para formar la cartera. En este sentido, estos derivados estarían creando valor para los inversionistas.

Sin embargo, no todas las opiniones han sido favorables a este tipo de instrumentos. Como sucede frecuentemente con los derivados de cualquier tipo, las opiniones son muy encontradas y, por ello no es extraño encontrar posturas extraordinariamente críticas. A veces, los ataques más duros contra los productos estructurados surgen desde dentro del mismo sistema financiero. Algunas críticas surgen motivadas por la expansión de los llamados fondos de cobertura y su papel activo en los mercados de los derivados crediticios. Una preocupación con el desarrollo de estos fondos es que todos sus gestores sigan las mismas estrategias. En este caso, la adopción de una estrategia errónea podría crear una crisis sistemática. Otras veces, la crítica tiene algo de titular periodístico. Así, los derivados de tercera generación han sido denominados «bombas de tiempo», «armas financieras de destrucción masiva», o el «producto más tóxico de todos los que se pueden encontrar en los mercados financieros».

Este último tipo de críticas debería deslindarse de las producidas a partir de una reflexión más seria sobre el papel de los derivados crediticios y de la observación de su comportamiento en los mercados. A este respecto resulta interesante el trabajo de Partnoy y Skeel ${ }^{10}$, que examinan los CDS y los CDO presentando las ventajas e inconvenientes de cada uno de estos derivados. Entre las ventajas que hallan están la ampliación de oportunidades para efectuar coberturas, aumento de la liquidez, reducción de los costes de transacción y la ampliación de un mercado potencialmente más eficiente para negociar el riesgo crediticio. Entre los inconvenientes aparecen los problemas de riesgo moral, falta de transparencia, posibilidades de riesgo sistémico, cos-

${ }^{9}$ Gibson, M. «Understanding the risk of Synthetics CDOs», Federal Reserve Board, Working Paper, julio 2004.

${ }^{10}$ Partnoy, F. y D.A. Skeel Jr, «The Promise and Perils of Credit Derivatives», University of Pennsylvannia Law School, Paper 125, 2006. 
tes de transacción elevados para los CDO y una tendencia a fijar de forma incorrecta el precio del riesgo crediticio.

Este último factor, posiblemente sea el más problemático. Phelan y Alexander ${ }^{11}$ enumeran diversas cuestiones que dificultan la posibilidad para desarrollar modelos que permitan evaluar correctamente el riesgo crediticio. Entre estos destacan, la falta de liquidez (transacciones) respecto a algunas emisiones, la dificultad para observar las verdaderas probasbilidades de insolvencia, la necesidad de inferir estas probabilidades a partir de las calificaciones otorgadas por las agencias o por métodos puramente subjetivos, la dificultad para agregar el riesgo crediticio teniendo en cuenta las posibles correlaciones que se pueden presentar entre diversas emisiones, $\mathrm{y}$, finalmente, la dificultad para determinar las ratios capital propio/deuda apropiadas que han de proporcionar un colateral adecuado frente a posibles insolvencias.

El problema de una fijación incorrecta de los precios ha estado en el punto de mira de los debates más recientes. Antes de la crisis del mercado subprime, la preocupación ha surgido a partir de la observación de que se han realizado numerosas emisiones de deudas corporativas y créditos a unos tipos de interés con un diferencial muy pequeño respecto a los tipos de interés libres de riesgo, por un lado, y la generación de numerosos CDS vendiendo protección respecto a estas emisiones o créditos, con el peligro latente de perturbación en los mercados financieros en el caso de que varias de estas emisiones fueran insolventes ${ }^{12}$. Por otra parte, los análisis recientes, también ha puesto énfasis al señalar los efectos que el funcionamiento de los mercados de los derivados crediticios podría tener respecto a la transferencia de riesgos. $\mathrm{Si}$ bien en un principio, los bancos pueden transferir el riesgo crediticio a terceros, éstos a su vez son bancos o fondos de coberura normalmente apalancados para efectuar las compras de estos riesgos y su actividad depende de líneas de créditos que los bancos les conceden. En este sentido, un aumento de las tasas de insolvencia devuelve el riesgo otra vez a los bancos, bien a través de su exposición directa a estos instrumentos o indirecta como financiadores de las compras de estos riesgos por parte de terceros. En este sentido, el desarrollo del mercado de los derivados crediticios para permitir la trasnferencia de riesgos habría creado un nuevo riesgo que anularía las ventajas de la transferencia inicial.

${ }^{11}$ Phelan, K. y C. Alexander, «Different Strokes», Risk, octubre 1999, Credit Risk Supplement.

12 Esta amenaza para la estabilidad de los mercados financieros se expresa claramente en el Informe anual del BIS para el año 2006. 


\section{Los $C_{\text {REDIT }}$ DEFAULT $S_{\text {WAPS }}(C D S)$}

Los credit default swaps (CDS) constituyen el derivado de tercera generación más utilizado contando con un mercado caracterizado por su alta liquidez. Un CDS es un contrato bilateral, estandarizado de acuerdo con los protocolos de la ISDA ${ }^{13}$, negociado fuera de mercados organizados (over the counter), en el cual una de las contrapartes, llamada comprador de protección, mediante el pago trimestral de un porcentaje sobre el valor nocional de un crédito correspondiente a una entidad específica ${ }^{14}$ y durante un período de tiempo determinado, transfiere a la otra contraparte, llamada vendedor de protección, el riesgo específico asociado con este crédito. Si se produce algún «acontecimiento crediticio», especificado en el contrato durante el período de vigencia de éste, el vendedor de protección pagará el nominal del crédito de la entidad especificada recibiendo, en contrapartida, del comprador de protección algún tipo de «activo de referencia» especificado en el contrato original, que representa la ratio de recuperación de este crédito. En otros casos, el contrato se cancela a través de un pago monetario del vendedor de protección al comprador de protección por un importe equivalente a la pérdida que ha sufrido el banco por el impago del crédito. Estas diferencias en la forma de cancelar un contrato ante un evento crediticio hace que normalmente se hable de CDS en especie o en caja. Hecha esta compensación el contrato se extinguirá, sin que el comprador de protección tenga que realizar nuevos pagos de primas.

Definido de esta forma, un CDS no es más que una especie de contrato de seguro, en donde la prima, llamada técnicamente spread o diferencial representa el precio del riesgo asociado con el crédito concreto que se quiere asegurar, aunque también podría interpretarse como una opción de venta (put), en el sentido que permite al comprador de protección vender el crédito al vendedor de protección por un precio superior al que tendrá el crédito tras producirse el acontecimiento crediticio.

${ }^{13}$ La ISDA es el acrónimo correspondiente a la International Swaps and Derivatives Association. La estandarización de acuerdo con los protocolos de la ISDA es importante pues elimina muchos riesgos de tipo legal que podrían presentarse ante los acontecimientos crediticios.

${ }^{14}$ El término crédito debe entenderse en un sentido amplio. Lo que se negocia a través de un CDS es el riesgo crediticio ya sea de una empresa que emite un bono o ha obtenido un préstamo bancario o de un emisor de deuda soberana. . 
¿Cómo se calcula la prima? Aunque existen numerosos modelos todos ellos remiten a procesos en los que se calcula la probabilidad de insolvencia y el valor de recuperación del activo asegurado. De acuerdo con Duffie y Singleton ${ }^{15}$, los modelos existentes pueden clasificarse como modelos estructurales y modelos de forma reducida. El primer tipo de modelos exige poder cuantificar determinados valores propios de la entidad de referencia para poder calcular la probabilidad de insolvencia, mientras que el segundo calcula la probabilidad de insolvencia y el valor de recuperación a partir de datos que se pueden encontrar en el mercado. No hay que decir que el segundo tipo de modelización es más popular que el primero.

Para ver como los datos existentes en los mercados pueden servir para poner precio a un CDS, es conveniente empezar indicando que el vendedor de protección en un CDS actúa de una manera equivalente a si comprara el crédito al banco mediante un crédito por el mismo importe y plazo de amortización que le ha concedido otro banco, a un tipo igual al LIBOR. Puesto que el vendedor de protección ahora es el propietario del crédito tiene derecho a percibir los intereses que concede este crédito y la parte de devolución del capital correspondiente. Imaginemos ahora que los intereses que le proporciona al inversor el crédito adquirido son iguales al euribor más 50 puntos básicos $(50 \mathrm{pb})$ y que éste hace una permuta de activos de modo que dentro de un año entregará los intereses obtenidos por el crédito a cambio del LIBOR más $30 \mathrm{pb}$. Si ahora calculamos todos los flujos de caja generados por esta operación el beneficio neto que le queda al inversor en el caso de que el crédito no presente ninguna incidencia es igual a $30 \mathrm{pb}$ por cada 100 euros de valor nominal del crédito.

Es por ello, que en ausencia de arbitraje, la prima a percibir por el vendedor de protección en un CDS para un crédito idéntico al del apartado anterior debería ser igual a $30 \mathrm{pb}$, y en general igual al diferencial respecto al LIBOR en una permuta de activos. No obstante, en la práctica suele haber algunas diferencias y las primas en los CDS suelen ser algo mayores que los diferenciales observados en las permutas de activos respecto al LIBOR. A esta diferencia se la llama «la base» y acostumbra a variar de acuerdo con el sentimiento del mercado. Así, por ejemplo, cuando se comparan el diferencial que paga el bono de una determinada corporación respecto a un activo libre de riesgo y el diferencial respecto al LIBOR que cuesta comprar protección para esta misma corporación para contratos que tienen el mismo vencimiento que el bono puede verse como ante una noticia adversa el precio de la protección

${ }^{15}$ Duffie, D. y K. Singleton, «Modelling Term Structures of Defautable Bonds», Review of Financial Studies, vol. 12, págs. 687-720, 1999. 
aumenta más que proporcionalmente que el diferencial del bono, mientras que en condiciones normales los dos diferenciales son prácticamente idénticos. Esto es así, tanto porque la noción de acontecimiento crediticio que figura en un CDS es más amplia que la que puede afectar al bono en cuestión como por el hecho de que el comprador de protección dentro de un conjunto de activos de referencia puede entregar al vendedor aquel activo que le resulte más barato.

Obviamente, el hecho de que los CDS sean contratos bilaterales en donde el objeto asegurado se refiere a un crédito concreto de una entidad concreta, hace que los porcentajes sobre el valor nominal del crédito varíen para cada CDS al igual que sucede en los mercados de permutas de activos. En algunos casos, la prima puede ser de unos pocos puntos básicos mientras que en otros la prima es de algunos centenares puntos básicos. En este sentido, las primas reflejan como los vendedores de protección evalúan la exposición al riesgo de determinadas empresas y corporaciones.

Los CDS nacieron como un medio mediante el cual los bancos podían ofrecer cobertura al riesgo que habían asumido al conceder determinados créditos, pero siendo el CDS un instrumento derivado pronto se observó que podía crearse un mercado en el que no hacía falta que el comprador de protección tuviera en su balance ningún crédito. Cuando no se busca una cobertura al riesgo crediticio sobre un préstamo que se ha concedido, el interés de este mercado está en las variaciones que normalmente experimentan las primas sobre las entidades de referencia. Si se cree que la exposición al riesgo de una determinada entidad va a aumentar en el futuro, entonces resulta interesante comprar protección ahora para venderla en el futuro cuando será más cara. Por el contrario, si se cree que la exposición al riesgo de una determinada entidad va a disminuir, entonces es adecuado entrar en el mercado de los CDS para vender protección. Obviamente, vender protección es una actividad con riesgos importantes. El comprador de protección puede reembolsarse sumas muy importantes de dinero en el caso de que se produzca un acontecimiento crediticio, aunque pueden darse situaciones que podrían llegar a resultar paradójicas. ${ }^{16}$ Es por ello, que los ven-

${ }^{16}$ Puesto que el volumen de CDS sobre una determinada emisión de bonos puede ser muy superior al volumen de bonos que hay en circulación, ante un evento crediticio podría darse el caso de que en los CDS en especie los compradores de protección hicieran una demanda tan elevada de bonos que al final el coste de los bonos de esta empresa fuera igual al nominal de la emisión asegurada de modo que su beneficio se reduciría a cero. La ISDA recomienda en estos casos que se celebre una subasta que fije un valor teórico para estos bonos y que el contrato se salde en caja. 
dedores de protección deben también procurar cubrirse de alguna manera frente al riesgo, ya sea entrando en un contrato en el que van a ser la contraparte que va a comprar protección, ya sea vendiendo en corto acciones de la corporación que se ve afectada por el acontecimiento crediticio ${ }^{17}$.

Estos riesgos, sin embargo no han impedido la extensión de los CDS como instrumento derivado de tal manera que la liquidez de su mercado ha permitido construir otro derivado sobre el mismo en forma de índice. Los índices relativos agrupan según los casos 100 o 150 nombres propios y están segmentados geográficamente. Así existen índices para Estados Unidos, Europa y Asia. El índice más conocido es el iTRAXX. El valor de estos índices es importante en la medida que resumen las condiciones existentes en los mercados crediticios, y como en cualquier índice bursátil periódicamente entran y salen nombres propios en la lista de las entidades seleccionadas.

\section{III.1. El funcionamiento de los CDS}

La operativa de un CDS puede representarse a través del siguiente ejemplo. Supongamos que el Banco A ha concedido un crédito asegurado a la empresa B por valor de 100 millones de euros, a un plazo de 8 años. Inmediatamente después busca proteción para ese crédito por lo que entra en el mercado de los CDS con la siguiente transacción: Mediante el pago a la contraparte C de 24 pb anuales por cada 100 euros de nominal, obtiene protección por valor de 50 millones de euros durante 5 años. Si se produjera algún acontecimiento crediticio $\mathrm{C}$ pagará a A 50 millones de euros. A cambio A entregará a $\mathrm{C}$ bonos de la empresa B por un valor nominal de 50 millones de euros. Los acontecimientos crediticios que se prevén son: a) que la empresa B no cumpla con los compromisos acordados con el Banco A, b) que la empresa $\mathrm{B}$ deje de pagar cualquier crédito que haya recibido de cualquier otro banco, o en otros créditos no asegurados en el banco A y c) que la empresa $\mathrm{C}$ deje de pagar o reestructure alguna emisión de bonos que esté en circulación.

El interés de este ejemplo radica en que los términos del credit default swap sólo

${ }^{17}$ Partnoy y Skeel, art. cit., págs. 21-22, indican que existe el riesgo de que la parte vendedora de protección pueda precipitar el acontecimiento crediticio si las ganancias que le pueden reportar las ventas en corto más el activo de referencia que reciba son superiores al pago que tiene que hacer al comprador de protección y citan un caso concreto en el que esta situación podría haberse dado. 
se ajustan parcialmente a los datos del crédito concedido por el banco A a la empresa B. Mientras el crédito tiene un nominal de 100 millones la protección comprada sólo lo es por 50 millones. El plazo del crédito es de 8 años, mientras que la duración del CDS es de 5 años. Finalmente, el acontecimiento crediticio hace referencia a situaciones de impago distintas a las del crédito concedido. Finalmente, en el caso de un acontecimiento crediticio el Banco $\mathrm{A}$ entrega al vendedor de protección $\mathrm{C}$ un activo distinto del crédito concedido a la empresa B.

Los ingresos del vendedor de protección son en este ejemplo de 120.000 euros anuales, que se cobran a razón de 30.000 euros cada trimestre. Si no se produce ningún acontecimiento crediticio, entonces el CDS proporcionará al vendedor de protección en este caso unos ingresos de 600.000 euros.

En el caso de que se produjera un acontecimiento crediticio, entonces el vendedor de protección tendría que pagar al Banco A 50 millones de euros recibiendo a cambio bonos por un valor nominal de 50 millones de alguna emisión realizada por la empresa B. Si por ejemplo estos bonos cotizan al 60\%, el banco A los compra por 30 millones, lo cual representa una ganancia neta de 20 millones. En el caso de que la empresa B terminara por no pagar el crédito inicial el hecho de que esté asegurado permitiría al Banco A recuperar prácticamente los 100 millones. En este sentido, el CDS permite al Banco A tener en todo momento la posibilidad de disponer de una cobertura parcial sobre su crédito, pero al mismo tiempo especular sobre la posibilidad de que se produzca algún acontecimiento crediticio relativo a la empresa $\mathrm{B}$ que le favorezca.

El hecho de que puedan realizarse CDS sin necesidad de que el comprador de protección tenga que tener el subyacente al que se refiere el contrato es lo que ha propiciado el importante desarrollo de este mercado. Este es un mercado en el que los participantes hacen apuestas respecto a la solvencia crediticia de determinados emisores, y en el que como en cualquier derivado las apuestas se pueden hacer de forma aislada o buscando algún tipo de cobertura. El vendedor de protección ante el riesgo de insolvencia puede cubrirse comprando protección o anulando el contrato inicial previo pago de una determinada cantidad. Cuando la participación se hace de forma desnuda, el riesgo es muy elevado.

\section{Collaterized Debt Obligations (CDO)}

En lugar de ofrecer una definición técnica de lo que es un CDO, diremos simplemente que un CDO es un fideicomiso o sociedad cuyo activo es un conjunto de títulos de deuda (ya sean créditos bancarios u obligaciones emitidas por empresas) 
que recibe el nombre de activos de garantía (collateralized asstes) y cuyo pasivo son un conjunto de obligaciones emitidas por el CDO, que reciben el nombre de obligaciones de deuda. Al frente del CDO hay un administrador de activos, que se encarga de colocar las obligaciones entre los inversores y con los fondos obtenidos comprará los activos del CDO. Posteriormente, se encargará de acuerdo con unas reglas preestablecidas del pago los intereses y, en su día, el principal correspondientes a las obligaciones emitidas por el CDO.

Las obligaciones emitidas por el CDO son de distintas clases, recibiendo el nombre de rodajas (tranches) ${ }^{18}$. Cada rodaja tiene una calificación distinta. Según la calificación obtenida la rodaja recibe un nombre específico. Así, las rodajas con calificación comprendida entre AAA y A reciben el nombre de senior, las rodajas con calificación comprendida entre $\mathrm{BBB}$ y $\mathrm{B}$ se denominan mezanine, mientras que las rodajas sin calificar reciben el nombre de junior o simplemente equity. Aunque los activos de garantía que forman el CDO pueden responder a activos con una relación riesgo/rendimiento distinta, la denominación de las rodajas depende de la forma en que se distribuyen los rendimientos generados por los activos entre los obligacionistas. Así, es posible generar diversas rodajas con diversas calificaciones con una cartera de activos constituida por un único activo. Esto permite redistribuir el riesgo asociado a un determinado activo y ajustarlo a los deseos de distintos inversores con un apetito diverso respecto al riesgo. Esta redistribución incorpora un instrumento derivado implícito indispensable para poder alterar la distribución de los riesgos y rendimientos de las obligaciones respecto a la incorporada en los activos de garantía.

En general, las rodajas senior son las que constituyen la mayor proporción de las obligaciones emitidas. Esto es fácilmente comprensible pues proporcionan los fondos para adquirir los activos de garantía a un precio menor al de las otras rodajas. En algunos CDO se incluye incluso una rodaja super senior que al gozar de mayor protección que la rodaja senior permite aún un coste de financiación más barato.

Los motivos para crear un CDO son diversos. En algunos casos, el CDO se crea a instancias de un banco o una sociedad hipotecaria como una forma de transferir riesgos o para eliminar activos de su balance y reducir los requisitos de capital. En otros casos, el promotor de un CDO quiere beneficiarse del posible diferencial entre

${ }^{18}$ El término tranche utilizado en la terminología de los CDOs proviene del francés traunche que tiene distintos significados en castellano tales como rebanada (de pan), rodaja (de limón), loncha (de jamón) o porción (de queso). Aquí, la hemos traducido por rodaja. 
el rendimiento ofrecido por los activos del CDO y los pagos a realizar a los obligacionistas de cada tramo.

Por otra parte, en la selección de los activos de garantía es habitual buscar dentro de una determinada calificación aquellos que tienen un precio más barato en el mercado. Uno de los problemas asociados con este procedimiento es asignar el riesgo de los activos de garantía exclusivamente en función de la calificación obtenida. El precio en el mercado de deuda depende de la calificación obtenida, pero también de otras variables. Por ello, dentro de una misma calificación la dispersión de precios puede responder a diferencias objetivas de riesgo, en lugar de una fijación de precios incorrecta por parte de los participantes en el mercado.

\section{IV.1. Tipos de CDO}

No todos los CDO que existen en el mercado son iguales. El CDO que hemos caracterizado corresponde al llamado CDO de caja. Pero existen muchos CDOs que en lugar de invertir en un conjunto de activos de garantía lo que hace es vender protección a través de todo un conjunto de CDS que puede abarcar hasta 100 nombres propios. En este caso, el CDO recibe el nombre de CDO sintético. En este tipo de CDO los inversionistas reciben las primas comprometiéndose a compensar a la contraparte correspondiente en caso de que se produzca un acontecimiento crediticio. Como en cualquier CDO las primas recibidas son reunidas y reestructuradas de forma que los acontecimientos crediticios serán liquidados en primer lugar a partir de la rodaja equity y sólo a partir de un determinado volumen de acontecimientos crediticios las otras rodajas entrarán a indemnizar a quienes han adquirido protección. No obstante, en muchos casos, para garantizar la solvencia de los CDS en los que el CDO entra a formar parte, los inversores en este tipo de CDO entregan cantidades equivalentes por el valor nominal de los CDS. En este caso el CDO invierte este dinero en activos libres de riesgo de manera que los inversores cobran los intereses de estos activos más los spreads correspondientes a los CDS. En el caso de un acontecimiento crediticio el CDO vende una parte de sus activos libres de riesgo, imputando la pérdida de estos activos a la rodaja correspondiente.

Por otra parte los CDO pueden ser estáticos o dinámicos. En un CDO estático los activos de garantía se seleccionan cuando se constituye el CDO y forman parte de su cartera hasta la extinción del CDO. En los CDO dinámicos, el gestor tiene capacidad para alterar la composición de los activos de garantía para la búsqueda de activos que proporcionen una mayor rentabilidad o tengan un menor riesgo. La gestión dinámica es un tema complejo que normalmente añade un riesgo adicional. 
De la misma manera que en el mercado de los CDS han aparecido índices, en el de los CDO han surgido los llamados CDO cuyos activos de garantía están formados por otros CDO. La atracción que ofrecen estos CDO reside en que ofrecen un rendimiento más alto hasta que se produce un determinado número de insolvencias. Sin embargo a partir de este valor las pérdidas son mayores que en el caso de los CDO tradicionales.

A partir del año 2004, empezaron a ser frecuentes una clase especial de CDO formados por una única rodaja, normalmente de tipo mezzanine. Estos CDO generalmente se forman como una segregación a partir de un conjunto de activos de garantía subyacentes y son vendidos a un único inversor el cual determina el rendimiento que quiere obtener y de este modo la horquilla de las pérdidas que va a asegurar. Puesto que el resto de los activos permanecen dentro de la estructura de capital del CDO y no han sido transferidos a ningún inversor plantean riesgos que tienen que ser cubiertos mediante una gestión dinámica, del tipo cobertura delta típica de todos los derivados.

\section{IV.2. El funcionamiento de los CDO}

A continuación se va a explicar a través de un ejemplo como funcionan los CDOs. Supongamos un CDO cuyo único activo son un conjunto de obligaciones emitidas por una corporación, con calificación BBB, por un valor nominal de 1.000 millones de euros, plazo de vencimiento a 10 años e interés fijo igual al tipo oficial de las obligaciones a 10 años referenciado por el Banco Central Europeo en el momento de la emisión más 400 pb. Las obligaciones emitidas por el CDO, están repartidas en tres rodajas cuyos rendimientos ofrecidos a los inversores se presentan en la siguiente tabla:

\begin{tabular}{|lrcc|}
\hline \multicolumn{4}{c|}{ ESTRUCTURA DEL CDO } \\
\hline RODAJAS & \multicolumn{1}{c|}{ VALOR } & CALIFICACIÓN & RENDIMIENTO \\
\hline SENIOR & 900.000 .000 & AAA & LIBOR $+175 \mathrm{pb}$ \\
MEZZANINE & 70.000 .000 & BBB & LIBOR $+425 \mathrm{pb}$ \\
EQUITY & 30.000 .000 & Sin calificar & residual \\
CDO & 1.000 .000 .000 & $\mathrm{~A}$ & \\
\hline
\end{tabular}


En cualquier CDO hay una serie de aspectos que llaman inmediatamente la atención. En primer lugar, que a pesar de que el único activo tenga calificación BBB algunas rodajas obtengan la calificación AAA. Esto es posible porque los compradores de las rodajas sin calificar y los de la calificada como BBB asumen el riesgo de compensar hasta cierto límite a los compradores de la rodaja AAA en el caso de que se produzcan impagos. Este límite normalmente se sitúa a un nivel muy superior al que señalan las probabilidades de insolvencia, por lo que el poseedor de una rodaja calificada como AAA tiene un activo casi libre de riesgo, pero con una remuneración superior. Para ser más precisos en el CDO de nuestro ejemplo, los compradores de la rodaja sin calificar, asumen los primeros 30 millones de pérdidas que puedan ocurrir mientras que los de la rodaja calificada como BBB asumen las pérdidas comprendidas entre los 30 y los 100 primeros millones de pérdidas. Los poseedores de la rodaja calificada como AAA, sólo tendrán que asumir las pérdidas que asciendan a más de 100 millones de euros. Es fácil advertir que los compradores de la rodaja senior, de hecho están renunciando a parte del rendimiento que ofrece el activo de garantía a cambio de comprar a los poseedores de la rodaja equity protección limitada frente a posibles pérdidas. Viceversa, los poseedores de la rodaja equity, venden protección a las otras dos rodajas a cambio de compensar el riesgo de esta protección con un mayor rendimiento que el que obtendrían si hubieran adquirido directamente la obligación que representa a los activos de garantía. La posición de los poseedores de la rodaja mezzanine ocupan una posición mixta, pues compran protección de la rodaja equity, al tiempo que venden protección adicional a los poseedores de la rodaja senior. Puesto que el valor de la protección que venden es mayor que el valor de la protección que compran, el rendimiento de su inversión en el CDO debería ser mayor que el que obtendrían si hicieran un inversión de 70 millones de euros adquiriendo directamente el activo de garantía.

Por consiguiente, lo que hace el gestor de un CDO es vender simultáneamente una obligación que está en su activo, modificando sus características de manera análoga a la que lo podrían hacer los compradores en el mercado libre si a continuación hicieran determinadas transacciones en el mercado de CDS. Estas operaciones realmente serían muy complejas para carteras muy diversificadas.

En el ejemplo, también puede observarse que aunque los compradores de las rodajas tipo mezzanine y equity invierten un valor relativamente pequeño en la adquisición de los activos de garantía (10\% en nuestro caso), concentran la mayor parte de los riesgos. Es por eso que su inversión se dice que es apalancada y, por consiguiente, más expuesta a los cambios en la volatilidad. Según como evolucione ésta, estas rodajas pueden recibir recalificaciones a la baja que reducen el valor de la inversión. 
Es importante comprender a partir de aquí que la inversión en las rodajas mezzanine y equity comporta un riesgo muy alto. Piense que en lugar de invertir 100 millones en estas rodajas se invierte la misma cantidad adquiriendo 100 bonos distintos de 1 millón cada uno. Si en caso de insolvencia, se llega a recuperar el 50\% del valor de cada bono, entonces es preciso un nivel de insolvencias del $100 \%$ en la cartera de bonos y ésta será la pérdida máxima a la que se estará expuesto. Para el inversor en la rodaja equity, no obstante, un nivel de insolvencias del 3\% ya le comporta este nivel de pérdidas, que puede ir aumentando si aumenta el nivel de insolvencias. Para el inversor en la rodaja mezzanine las pérdidas alcanzan al 50\% de su inversión cuando las insolvencias alcanzan el 13\%, y pueden continuar aumentando al igual que en el caso anterior hasta alcanzar el $100 \%$ del capital invertido.

Aunque nuestro ejemplo, aquí sólo incluye un activo, éste no es el caso habitual. Dado el nivel de riesgo que presentan las inversiones en un CDO, la diversificación de los activos de garantía es importante, a la hora de fijar un precio para las distintas rodajas de un CDO, el llamado riesgo de correlación, referido a la probabilidad de que se produzca una insolvencia en un determinado activo de garantía teniendo en cuenta que se ha producido una insolvencia en otro activo de garantía de la misma cartera. Este es el aspecto más crucial en la formación del precio de las obligaciones a emitir por el CDO. En algunos casos, sin embargo, hallar este riesgo de correlación es muy difícil por las características de la composición de los activos de garantía.

El segundo rasgo destacable de nuestro ejemplo es que a pesar de que el activo de garantía ofrece un rendimiento fijo, el $97 \%$ de las obligaciones emitidas por el CDO ofrecen una remuneración a tipo variable basadas en el LIBOR más un determinado número de puntos básicos. Esto no representa un gran problema, pues en este caso, el gestor de los activos del CDO puede dar cobertura al riesgo asociado con estas estructuras distintas en los flujos de ingresos y pagos a través de un swap sobre tipos de interés en relación a un nominal de 970 millones (el valor nocional de la rodaja senior) por el cual cada año pagará, por ejemplo, el tipo oficial correspondiente a las obligaciones a 10 años más 100 pb y recibirá a cambio el LIBOR. Si el tipo del LIBOR es menor que el de las obligaciones a 10 años más 100 pb, este swap de intereses provocará pérdidas en el CDO, las cuales también serán financiadas por las rodajas tipo equity y mezzanine (si fuera necesario).

Hechas estas precisiones, se puede pasar a calcular el rendimiento obtenido por cada una de las rodajas del CDO y compararlas con las que se habrían obtenido cuando el tipo oficial de las obligaciones a 10 años es del 4,65\% y los inversores hubieran adquirido estos activos en los mercados de deuda corporativa, sin invertir sus capitales en las obligaciones del CDO. Sobre los pagos realizados, supondremos que 
existen unos costes de gestión del 1\% sobre el valor de los cupones recibidos. El siguiente cuadro muestra los rendimientos que se obtendrían si los activos de garantía se adquieren fuera del CDO.

\begin{tabular}{|c|c|c|c|}
\hline \multicolumn{4}{|c|}{ RENDIMIENTO ANUAL DE LOS ACTIVOS DE GARANTÍA EN EL MERCADO } \\
\hline INVERSIÓN & CUPONES & COMISIONES & RDTO. NETO $(\%)$ \\
\hline 900.000 .000 & 77.850 .000 & 778.500 & 8,5635 \\
\hline 70.000 .000 & 6.055 .000 & 60.550 & 8,5635 \\
\hline 30.000 .000 & 2.595 .000 & 25.950 & 8,5635 \\
\hline 1.000.000.000 & 86.500 .000 & 865.000 & 8,5635 \\
\hline
\end{tabular}

A continuación se procederá a calcular el rendimiento de esta misma inversión realizada a través de un CDO. Como en el cuadro que se acaba de exponer, los ingresos que percibe el CDO son iguales a un 8,65\% de una inversión de 1.000.000.000 de euros, es decir, 86.500.000 de euros. Pero a esta cantidad hay que añadirle el valor del LIBOR sobre 970.000.000 de euros y restarle el tipo oficial de las obligaciones a diez años más 100 pb, también sobre un nominal de 970.000 .000 de euros. Supongamos que el valor del LIBOR es del 5,23\%, en tanto que el tipo oficial de las obligaciones a 10 años es el 4,65\%. Los ingresos del CDO serán:

$$
\text { Ingresos del } \mathrm{CDO}=86.500 .000+50.731 .000-54.805 .000=82.426 .000 \text { euros }
$$

\section{¿Cómo se reparten?}

En un intento de ser lo más realistas posibles se utilizará una estructura de comisiones lo más parecida a la utilizada por los CDOs.

En primer lugar, hay unos gastos de establecimiento calculados como $150 \mathrm{pb}$ del valor total de los activos de garantía a pagar en 10 años. En nuestro ejemplo esto implica un pago anual de 1.500 .000 euros.

Una comisión igual a 50 pb sobre el valor nominal de los activos colateralizados. Los poseedores de la rodaja equity además pagan una comisión adicional de 25 pb sobre el valor nominal de los activos de garantía. Si no se producen insolvencias estas comisiones que se pagan para pagar el trabajo del gestor de los activos, serán de 5.000.000 y 2.500.000 euros, respectivamente.

A continuación vienen los pagos que deben hacerse a cada una de las rodajas: 
La rodaja senior recibirá un cupón igual al LIBOR + 175 puntos básicos, es decir, un cupón del 6,98\%. El pago por intereses será igual a 900.000.000 x 0,0698= 62.820 .000 euros.

La rodaja mezzanine cobrará un cupón igual al LIBOR + 425 puntos básicos, lo que equivale a un cupón del 9,48\%. El pago por intereses será de 70.000 .000 x 0,0873 $=6.111 .000$ euros.

Finalmente, la rodaja equity percibirá, el resto del dinero que haya en el fondo.

El siguiente cuadro muestra la distribución de los rendimientos obtenidos por el CDO.

\begin{tabular}{|lr|}
\hline \multicolumn{2}{|c|}{ DISTRIBUCIÓN DE LOS INGRESOS PERCIBIDOS POR EL CDO } \\
\hline Para amortización de los gastos de constitución & 1.500 .000 \\
Comisiones para el gestor de los activos (50 pb) & 5.000 .000 \\
Pago a la rodaja senior (900.000.000 x 0,0698$)$ & 62.820 .000 \\
Pago a la rodaja mezzanine (70.000.000 x 0,0948) & 6.636 .000 \\
Comisiones adicionales para el gestor (25 pb) & 2.500 .000 \\
Pago (residual) a la rodaja equity & 3.970 .000 \\
Pagos totales & 82.426 .000 \\
\hline
\end{tabular}

Ahora podemos comparar el rendimiento neto de las inversiones obtenidas según que la inversión se haga en el mercado de obligaciones corporativas o en las distintas rodajas ofrecidas por el CDO. Debido al mayor coste de las comisiones el rendimiento neto que va a todos los inversores en su conjunto es un $1,2209 \%$ menor que comprando los activos de garantía en un fondo de inversión en renta fija. Los costes de las comisiones de los CDOs en relación a otras entidades del mercado financiero a menudo es objeto de críticas.

\begin{tabular}{|lrlrc|}
\hline \multicolumn{5}{|c|}{ RENDIMIENTOS NETOS EN EL MERCADO Y EN EL CDO } \\
\hline INVERSIÓN & \multicolumn{1}{c|}{ MERCADO $(\%)$} & CDO $(\%)$ & DIFERENCIA \\
\hline 900.000 .000 & 8,5635 & Senior & 6,98 & $-1,5835$ \\
70.000 .000 & 8,5635 & Mezzanine & 9,48 & $+0,9165$ \\
30.000 .000 & 8,5635 & Equity & 13,2333 & $+4,6698$ \\
1.000 .000 .000 & 8,5635 & 7,3426 & $-1,2209$ \\
\hline
\end{tabular}




\section{IV.3. Los rendimientos del CDO en casos de insolvencias}

¿Qué sucede en el caso de que se produzcan algunas insolvencias?

Ya se ha visto como la prioridad en el cobro de los flujos de caja que proporcionan los CDO implican una protección para las rodajas de tipo senior y mezzanine frente a las de otro tipo. En un CDO cualquiera existen además cláusulas contractuales que proporcionan protección adicional a estas rodajas. Estas cláusulas se conocen como «señales de alarma» que se disparan y aplican en el caso de que las insolvencias reduzcan el valor nominal de los activos de garantía y/o los intereses más allá de ciertos límites prestablecidos. En este caso, los flujos de caja obtenidos por el CDO se redistribuyen al objeto de reponer el capital de las rodajas afectadas o a adquirir nuevos activos de garantía antes de que el resto de rodajas pueda recibir pagos en concepto de capital o intereses.

Las señales de alarma se definen a partir de cambios en el valor de las denominadas ratios $\mathrm{O} / \mathrm{C}$ e $\mathrm{I} / \mathrm{C}$, calculadas sobre cada rodaja, excepto para la rodaja equity a la que estas ratios no le son aplicables. La ratio $\mathrm{O} / \mathrm{C}$ se define como el cociente entre el valor nominal de los activos de referencia y el valor nocional de la rodaja más el valor nocional de las rodajas que le han comprado protección. La ratio I/C se define de manera análoga como el valor nominal de los intereses a repartir dividido por el valor nocional de los intereses correspondientes a una rodaja más el valor nocional de las rodajas que le han comprado protección más los gastos y comisiones correspondientes. La relación entre estas ratios y las señales de alarma es variable. De hecho, las estructuras de los CDO fijan las señales de alarma en valores más próximos o lejanos a los valores iniciales de las ratios como un instrumento para permitir cambios en los porcentajes de las diversas rodajas dentro de la estructura del pasivo de un CDO. De este modo, es posible ofrecer rendimientos similares a rodajas mezzanine y senior en dos CDO distintos y con un distinto peso de cada una de estas rodajas en cada $\mathrm{CDO}^{19}$.

Siguiendo con nuestro ejemplo, las ratios $\mathrm{O} / \mathrm{C}$ correspondientes a las rodajas senior y mezzanine son:

${ }^{19}$ Ver Lucas, D.C., L.S. Goodman y F.J. Fabozzi, «Collateralized Debt Obligations and Credit Risk Transfer», Yale ICF Working Paper, n 7, 2006. 


$$
\begin{aligned}
& O / C_{s}=\left(\frac{1.000 .000 .000}{900.000 .000}\right) \cdot 100=111,111 \\
& O / C_{m}=\left(\frac{1.000 .000 .000}{70.000 .000+900.000 .000}\right) \cdot 100=103,093
\end{aligned}
$$

Es obvio que cuanto mayor es el valor de la ratio O/C mayor es la seguridad que recibe la rodaja afectada por esta ratio.

Por su parte, las I/C ratios iniciales vienen dadas por:

$$
\begin{aligned}
& I / C_{s}=\left(\frac{86.500 .000}{62.820 .000+1.500 .000+5.000 .000}\right) \cdot 100=124,78 \\
& I / C_{m}=\left(\frac{86.500 .000}{62.820 .000+6.636 .000+1.500 .000+5.000 .000}\right) \cdot 100=113,88
\end{aligned}
$$

Las señales de alarma correspondientes a la ratio $\mathrm{O} / \mathrm{C}$ se establecen en valores de 105 y 101,05 para las rodajas senior y mezzanine respectivamente, mientras que las señales de alarma para la ratio I/C son 105 y 95, respectivamente

Supongamos ahora que se producen insolvencias que representan una pérdida del $2 \%$ en el valor de los activos de garantía.

Las ratios $\mathrm{O} / \mathrm{C}$ en la nueva situación vienen dadas por:

$$
\begin{aligned}
& O / C_{s}=\left(\frac{980.000 .000}{900.000 .000}\right) \cdot 100=108,88 \\
& O / C_{m}=\left(\frac{980.000 .000}{900.000 .000+70.000 .000}\right) \cdot 100=101,03
\end{aligned}
$$

En esta situación, puesto que la ratio se sitúa por debajo del umbral exigido de 101,05, el gestor de los activos antes de proceder a realizar ningún pago a los inversores de la rodaja equity deberá proceder a apartar 185.000 euros, bien para entregárselos a los poseedores de la rodaja senior, bien para destinarlos a la adquisición de nuevos activos de garantía para reponer parte del capital que se ha perdido.

Los flujos de caja generados por el CDO ahora serán, suponiendo que la permuta de intereses no ha variado, iguales a:

Ingresos del $\mathrm{CDO}=84.770 .000+50.731 .000-54.805 .000=80.696 .000$ 
La distribución de estos flujos de caja vendrá dada ahora por:

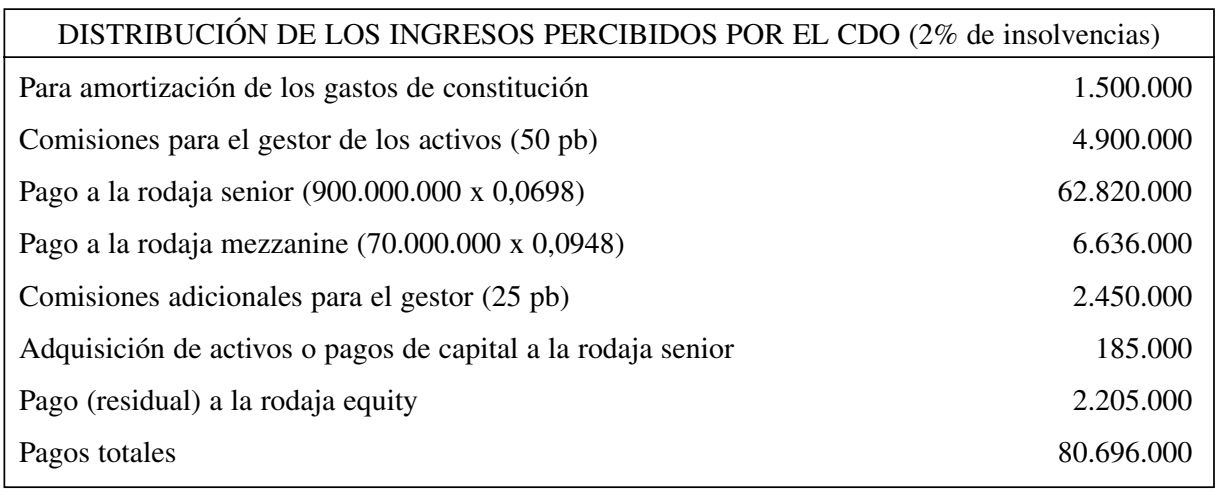

Las rentabilidades para los inversores en las rodajas senior y mezzanine no han variado. Todo el coste de las insolvencias es soportado por la rodaja sin calificar equity que ha visto como el flujo de caja que le llega ha pasado de 3.970.000 euros a 2.205.000 euros. La forma en que esto afecta a la rentabilidad de la rodaja equity depende del momento en que se producen la insolvencias, pues ello afecta al flujo de caja que constituye los ingresos del CDO. Si las insolvencias se producen al poco tiempo de constituirse el CDO tiene un efecto sobre la rentabilidad de la inversión en el CDO mucho mayor que si se producen hacia el final. En el ejemplo que se acaba de exponer, suponiendo que los activos de garantía del CDO se amortizaran al cabo de cinco años, puede simularse cuál sería el efecto sobre la rentabilidad de las diversas rodajas de pérdidas del $1 \%$ y del $2 \%$ de los activos de garantía según se produzcan entre el segundo y el quinto año, con la hipótesis adicional de que existe un valor de recuperación de los activos perdidos igual al 50\% que se cobra siempre al final del quinto año. Como muestra el siguiente cuadro si la pérdida de un $2 \%$ de ellos se produce el quinto año, la inversión en la rodaja equity proporcionaría un rendimiento medio anual del 6,48\%, mientras que si la pérdida de valor de los activos de garantía ocurriera el segundo año este rendimiento sería sólo del 2,24\%. Con una pérdida del $1 \%$, la rentabilidad de la rodaja equity resulta menos afectada ya que en este caso no se violan las ratios $\mathrm{O} / \mathrm{C}$ e I/C y, por consiguiente, no hay que apartar todavía intereses para reponer capital. 


\begin{tabular}{|cccccc|}
\hline \multicolumn{5}{|c|}{ RENDIMIENTOS DEL CDO BAJO DIVERSAS TASAS DE INSOLVENCIA } \\
\hline \multicolumn{5}{c}{ Rentabilidad de la inversión en el CDO $(\%)$} \\
\hline Insolvencia & Rodajas & $2^{\mathbf{o}}$ año & 3er año & $4^{\mathbf{o}}$ año & $5^{\mathbf{o}}$ año \\
$1 \%$ & $\mathrm{~S}$ & 6,98 & 6,98 & 6,98 & 6,98 \\
& $\mathrm{M}$ & 9,48 & 9,48 & 9,48 & 9,48 \\
& $\mathrm{E}$ & 7,79 & 8,32 & 8,84 & 9,37 \\
\hline $2 \%$ & $\mathrm{~S}$ & 6,98 & 6,98 & 6,98 & 6,98 \\
& $\mathrm{M}$ & 9,48 & 9,48 & 9,48 & 9,48 \\
& $\mathrm{E}$ & 2,24 & 3,29 & 4,34 & 6,89 \\
\hline
\end{tabular}

Lógicamente, si calcularamos tasas de insolvencia superiores, rápidamente los inversores en la rodaja equity experimentarían pérdidas y pronto también las experimentarían los inversores en la rodaja mezzanine. Este hecho muestra la importancia en la selección de los activos de referencia. Para que la inversión en las rodajas tipo equity y mezzanine resulten atractivas el porcentaje de insolvencias tiene que ser muy pequeño, al tiempo que la inversión tiene que hacerse sobre un activo que ofrezca un rendimiento atractivo. En el caso de que los activos de garantía estén constituidos por bonos, especialmente si son de alto riesgo, cuya amortización tendrá lugar en una fecha posterior a la de la liquidación del CDO, hay que evitar la pérdida de valor frente a subidas de tipos de interés o rebajas en la calificación de los mismos.

\section{LA CRISIS DEL MERCADO HIPOTECARIO EN Estados Unidos Y SU RELACIÓN CON LOS CDO}

Gran parte del interés actual por los derivados crediticios de tercera generación viene dado por el hecho de que los CDO (especialmente los de rodaja única) han incorporado una gran cantidad de las hipotecas del denominado mercado hipotecario subprime, muchas de las cuales no han sido reintegradas en los plazos previstos provocando numerosos embargos y subastas de viviendas y pérdidas importantes a los inversores en estos CDO.

El mercado subprime es un segmento tradicional del mercado hipotecario de los Estados Unidos caracterizado por la concesión de hipotecas a personas que no reúnen todos los requisitos para superar los valores exigidos en el llamado credit scoring. Por eso, a las hipotecas concedidas en ese segmento se las llama también hipo- 
tecas de alto riesgo, ya que las tasas de insolvencia son mayores que en los otros segmentos del mercado hipotecario. De acuerdo con Mason y $\operatorname{Rosner}^{20}$, la tasa de incidencias es 10 veces mayor que la de los mercados hipotecarios tradicionales.

Tradicionalmente, el mercado subprime era un mercado residual que representaba menos del $1 \%$ del volumen de hipotecas concedidas a principios de la década de los 90. Pero a partir de esta fecha empezó un crecimiento paulatino de modo que en 2003, ya suponía el 8,5\%. Ahora bien, el verdadero despegue no se produjo hasta el año 2004 cuando las hipotecas del mercado subprime pasaron a representar ya el $18,5 \%$, porcentaje que se incrementó en 2005 y 2006 hasta el 20,0\% y 20,1\%, respectivamente $^{21}$. En términos monetarios, las hipotecas concedidas en el período 2004-2006 ascendieron a 576, 625 y 600 mil millones de dólares.

Gran parte de estas hipotecas emitidas en el mercado subprime han sido titulizadas y adquiridas por los CDO. De forma paralela a lo sucedido con los volúmenes hipotecarios, las hipotecas subprime han aumentado su participación dentro de las emisiones de títulos respaldados por hipotecas. Las cifras correspondientes a las emisiones totales de títulos hipotecarios en 2004 y 2005 fueron de 1,8 y 2,1 billones de dólares, respectivamente. Las hipotecas del mercado subprime representaron el 19\% y el $22 \%$ del valor de todas las emisiones. Unos simples cálculos muestran que de todas las hipotecas concedidas por el mercado subprime en 2004 y 2005 el 62,94 y el $74,39 \%$ acabaron titulizándose. Los valores para 2006 posiblemente sean algo menores, pues a mediados de este año ya empezaron a circular rumores sobre el alarmante aumento del número de insolvencias.

Para comprender el auge del mercado subprime hay que observar la evolución de los precios de la vivienda en los Estados Unidos y como han evolucionado las prácticas en la concesión de préstamos en los mercados hipotecarios. Para ello, resulta muy interesante observar la evolución de los precios de la vivienda. La siguiente gráfica muestra la evolución del precio de la vivienda entre 1890 y 2005 en términos reales realizada por Robert J. Shiller.

${ }^{20}$ Mason, J.R y J.A. Rosner, «How Resilient Are Mortgatge Backed Securities to Collateralized Debt Obligation Market Disruptions?, documento de trabajo presentado el día 15 de febrero de 2007 en el Hudson Institute.

${ }^{21}$ Ver Joint Center for Housing Studies, The State of the Nation's Housing 2007, Harvard University Press, Tabla A-8, pág. 40. 
Figura 1. La evolución del precio de la vivienda en Estados Unidos (1890-2005)

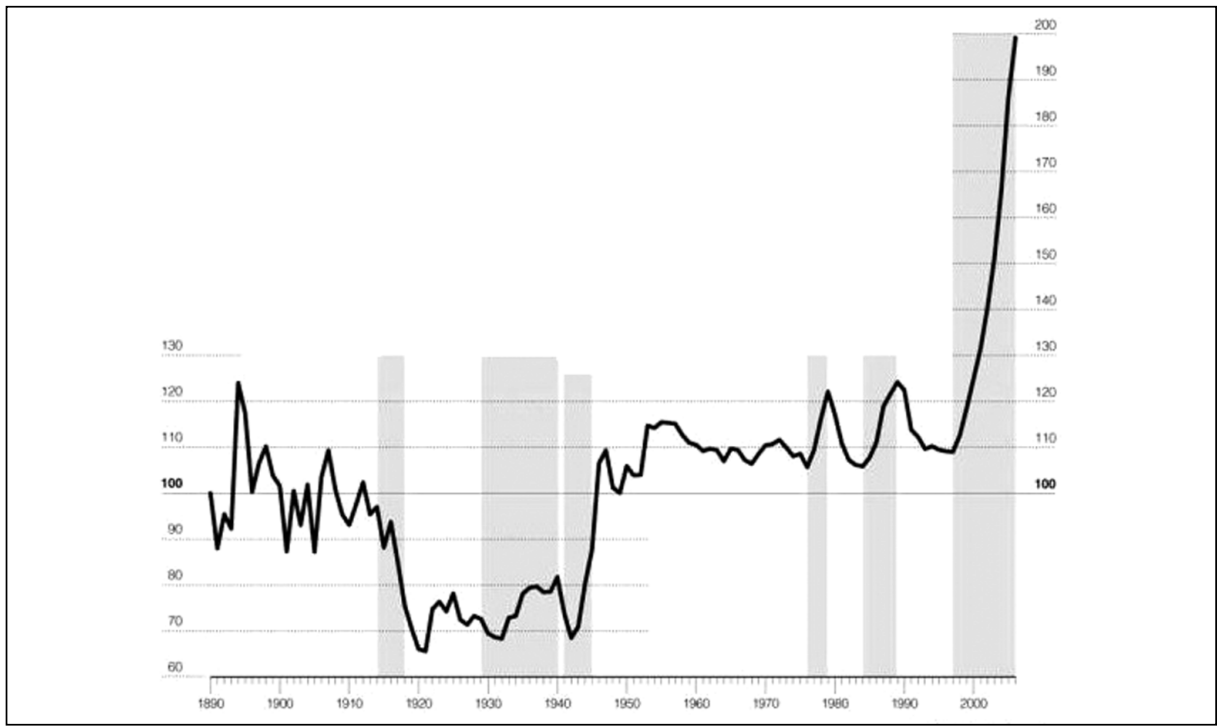

Fuente: Robert J. Shiller, Irrational Exhuberance, $2^{\mathrm{a}}$ ed. 2006.

La gráfica es altamente ilustrativa ya que muestra que una subida de precios de la vivienda de la magnitud experimentada a partir de 1997 es un fenómeno completamente inusual. En efecto, para hallar en los años de la muestra otro período en el que en términos porcentuales el precio de las viviendas subiera en la misma magnitud hay que retrotaerse a los años 1940. Pero en este caso, es fácil hallar las razones de la subida en el reajuste que se produce tras el período de crisis que se incia en 1929 y que mantuvo el PIB de la economía americana muy por debajo de su nivel potencial.

Observando el precio de la vivienda en el período 1950-1997, aunque hay fluctuaciones cíclicas, también se observa cierta reversión a la media. Aunque tanto en torno a 1977 como a 1987 se observan dos períodos en los que los precios reales de la vivienda experiementan crecimientos notables, éstos no superan el $20 \%$ y, además, son seguidos por bajadas prácticamente de la misma magnitud de modo que el nivel real de precios de las viviendas en 1997, en Estados Unidos, prácticamente era el mismo que en 1950.

Lo sucedido a partir de 1997 es otra historia. Gracias a los efectos de lo que ahora se llama la etapa de la «Gran Moderación», que redujo los elevados niveles de 
inflación de los años 70 y principios de los 80, los tipos de interés se situaron en el nivel mínimo de la década en un contexto de crecimiento sostenido. Y a pesar de que el precio de la vivienda empezó a aumentar, la evolución de los tipos de interés atenuaba el impacto de las subidas. Tampoco son despreciables los efectos que tienen los cambios en la concesión de hipotecas que empezaron a flexibilizar sus criterios para adaptarse mejor a las necesidades de sus clientes, así como el incremento de la demanda que hacen las llamadas «minorías». Todos estos efectos combinados hacen que en términos reales, el coste mensual medio de una hipoteca fuera un $30 \%$ menor que una década antes cuando para atajar la inflación, los tipos de interés alcanzaron valores muy elevados ${ }^{22}$.

Estas condiciones, se han mantenido prácticamente intactas durante toda la década que sigue a 1997. Excepto, una etapa recesiva de corta duración en 2001, la economía americana ha crecido de forma más que aceptable y los tipos de interés se han mantenido muy bajos, especialmente tras los sucesos del 11 de septiembre de 2001, cuando el tipo de interés oficial se situó en un $1 \%$ nominal. Eso permitió que incluso durante esa crisis el precio de la vivienda continuara aumentando, reforzándose por la continua modificación de las hipotecas que fueron haciéndose cada vez más flexibles.

Las subidas de tipos los de interés iniciadas a partir de 2004 combinadas con los aumentos de los precios de las viviendas empezaron a crear las primeras dudas respecto a la posibilidad de los mercados hipotecarios para sostener la burbuja inmobiliaria que se había creado, pues a pesar de los esfuerzos del mercado hipotecario para asumir las sucesivas subidas, éstas tuvieron como efecto aumentar, como se muestra en la Figura 2, el peso que representa el coste de las hipotecas dentro de las renta de las familias.

Como puede observarse, a partir del año 2004 se produce un aumento importante en el coste mensual de las hipotecas como porcentaje de la renta mensual de quienes tienen un préstamo hipotecario, aunque el porcentaje todavía es asumible. De hecho, en el llamado prime mortgatge market el porcentaje de incidencias se ha mantenido estable sin que el número de hipotecas que retrasan su pago más de 90 días haya superado el 1\%. Los efectos de la nueva situación se han manifestado sobre todo

${ }^{22}$ Ver Joint Center for Housing Studies, The State of the Nation's Housing: 1998, Harvard University, 1998. 
en el mercado subprime y en el llamado Alt-A market, que es un segmento del mercado hipotecario que se sitúa entre el prime y el subprime, donde la tasa de insolvencias ha pasado del $1 \%$ al 3\% entre 2004 y 2006.

Obviamente, lo representado en la Figura 2 es engañoso en la medida que es una media obtenida a partir de un conjunto de hipotecas originado en un período muy amplio y, por lo tanto, con precios medios de la vivienda muy dispares. Por ello, es preciso desagregar en la medida de lo posible algunos datos o aportar información complementaria que resulte relevante.

Figura 2. Porcentaje de la renta que representa el pago mensual de las hipotecas.

Estados Unidos (1994-2006)

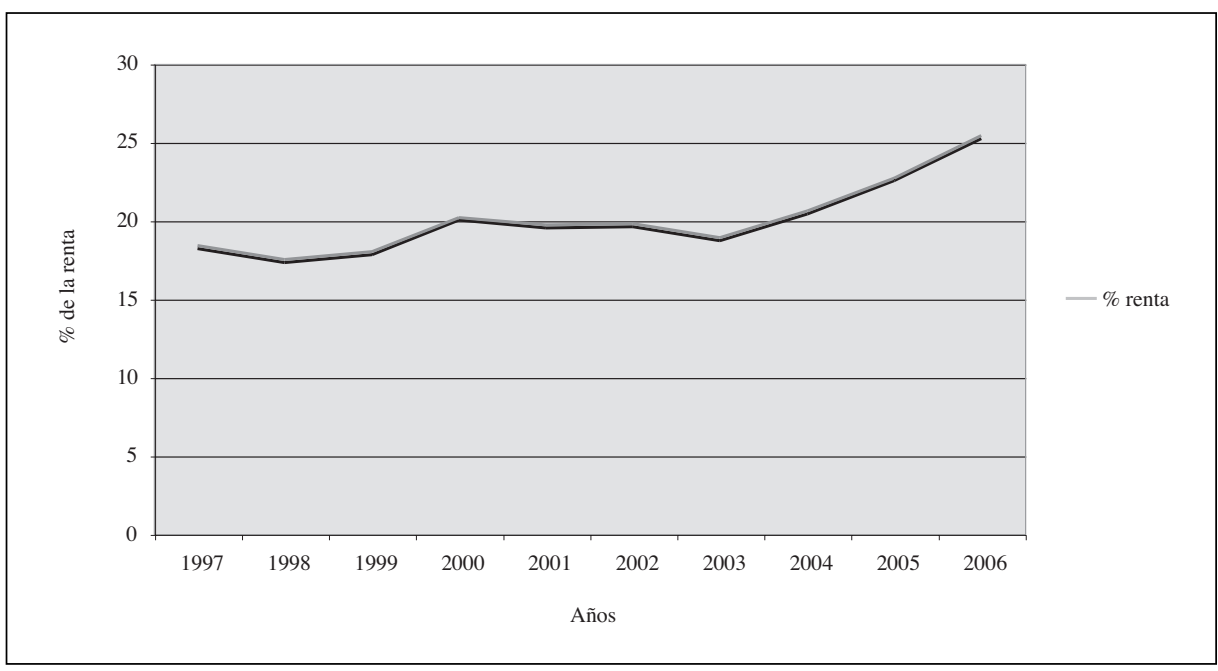

Fuente: Joint Center for Housing Studies, The State of Nation's Housing, 2007.

Quizás el dato más relevante es la evolución del porcentaje de hogares para los cuales el pago mensual de la hipoteca les representa una carga severa, en el sentido de que para atender al pago de la hipoteca hay que desprenderse de más del $40 \%$ de la renta. En 2001, el porcentaje de hogares para los que la hipoteca les representaba una carga severa era del 9,27\%. En 2005, esta cifra aumenta hasta el 10,83\%. Si, se contempla además cuáles son los valores de estos porcentajes para las familias de menos ingresos situadas en la primera decila de renta se puede ver que aumentan sensiblemente hasta situarse en el 62,87\% y el 67,06\% para los años 2001 y 2005.

Las familias con menos ingresos pueden recibir en Estados Unidos diversas ayu- 
das de la FHA (Federal Housing Association). No obstante, debido a la escasez de fondos federales, más de un $25 \%$ de las familias que podrían resultar beneficiadas no reciben ningún tipo de ayuda. Las ayudas a la vivienda, han pasado del 10,2 en 1998 al 7,7 en 2006 como porcentaje del presupuesto federal no destinado a defensa. Esta reducción en las ayudas podría explicar, por lo menos en parte, el auge experimentado por el mercado subprime.

Como se indicó al principio de esta sección la expansión del mercado subprime se ha producido en los primeros años del siglo XXI. Esta expansión es en cierto modo sorprendente porque la tasa de morosidad y procedimientos judiciales para recuperar las deudas es relativamente elevada y, en consonancia los tipos de interés sobre los créditos hipotecarios y otros gastos asociados son considerablemente mayores que en los otros segmentos del mercado hipotecario.

El informe del Joint Center for Housing Studies de la Universidad de Harvard del año 1999 cuando ya empezaba a notarse la influencia del mercado subprime expresaba claramente al respecto:

Una fracción de la actividad crediticia basada en tipos y comisiones elevadas es depredadora, siendo realizada por agentes que utilizan tácticas de venta agresivas o que se aprovechan injustamente de la ventaja que les proporciona el que los prestatarios no comprendan las características de los préstamos que se les ofrecen. Lo que es especialmente preocupante es el uso por parte de los prestamistas depredadores de tales tácticas para conseguir pagos mensuales que son demasiado elevados para que los prestamistas puedan hacerles frente o que reduzcan continuamente la proporción de capital que los hogares poseen en las viviendas a través de repetidas refinanciaciones que implican elevadas comisiones o costes de remodelización exagerados que acaban elevando el valor de la deuda hipotecaria pendiente (pág. 17).

Más o menos con las mismas palabras este juicio se repite en informes de años posteriores, poniéndose cada vez mayor énfasis en el riesgo que este mercado representaría en el caso de que los precios de la vivienda modificaran su tendencia. Pero, como muestra la Figura 1, los precios continuaron todavía aumentando hasta el año 2006.

Diversos autores han puesto énfasis en el hecho de que aunque los tipos de interés empezaron a subir en el año 2004, los tipos de interés continuaron siendo excesivamente bajos según la óptica de la llamada regla de Taylor y por lo tanto la política monetaria continuó siguiendo acomodaticia. Por si esto no fuera poco, los tipos de interés a largo plazo tampoco respondieron en la forma que era de prever, posible- 
mente debido al abundante ahorro generado en Asia y a los efectos de la globalización sobre los precios. Esto permitió que los precios de la vivienda siguieran subiendo y que el riesgo asociado al mercado subprime quedara oculto bajo una tasa de incidencias mucho menor que la tradicional ${ }^{23}$, pero creciendo y multiplicándose como las células en un proceso canceroso antes de manifestarse abiertamente.

La Figura 3 muestra la variación de los precios de la vivienda y los porcentajes de las hipotecas concedidas por el mercado subprime que estaban retrasadas en sus pagos más de 60 días o en proceso judicial. La gráfica pone de relieve como la tasa de variación de los precios de las viviendas se relaciona con los cambios en las tasas de morosidad y en el número de procedimientos judiciales que entablan las entidades financieras para recuperar el dinero prestado. Para valorar adecuadamente la interpretación de estos porcentajes merece la pena indicar que de acuerdo con la opinión de la Mortgatge Bankers Association ${ }^{24}$, entre que un crédito hipotecario entra en el juzgado y la posible venta de la vivienda en pública subasta existe todo un proceso de negociaciones que determina que sólo un $25 \%$ de los procedimientos judiciales entablados acaba en la subasta de la vivienda (pág. 36).

Ya se ha explicado antes cómo el aumento del precio de las viviendas aporta un call que reduce los incentivos a incumplir los pagos previstos en el contrato que materializa una hipoteca. Pero, hay algunos elementos adicionales de interés para entender mejor el mercado subprime, relacionados con las prácticas depredadoras de los agentes que intervienen en este mercado. La subida de los precios estimuló la construcción de nuevas viviendas hasta alcanzar un máximo en 2005. Esto amplió enormemente la capacidad del mercado hipotecario y la posibilidad de obtener beneficios. En este marco, las entidades financieras entraron en una dura competencia para captar el mayor número de clientes, y de este modo se dio un paso más en el proceso de adaptar las hipotecas a las teóricas necesidades de los clientes.

${ }^{23}$ Existe evidencia empírica que muestra una relación inversa entre la evolución del precio de la vivienda y el porcentaje de incidencias. Ver, por ejemplo, John B. Taylor, «Housing and Monetary Policy», Federal Reserve Bank of Kansas City, Symposium on Housing, Housing Finance, and Monetary Policy, 2007.

${ }^{24}$ Mortgatge Bankers Association, The Residential Mortgatge Market and Its Economic Context in 2007, MBA Research Monograph Series, 30 de enero 2007. 
Figura 3. Variación en precios, tasas demorosidad y procedimientos judiciales en el mercado subprime

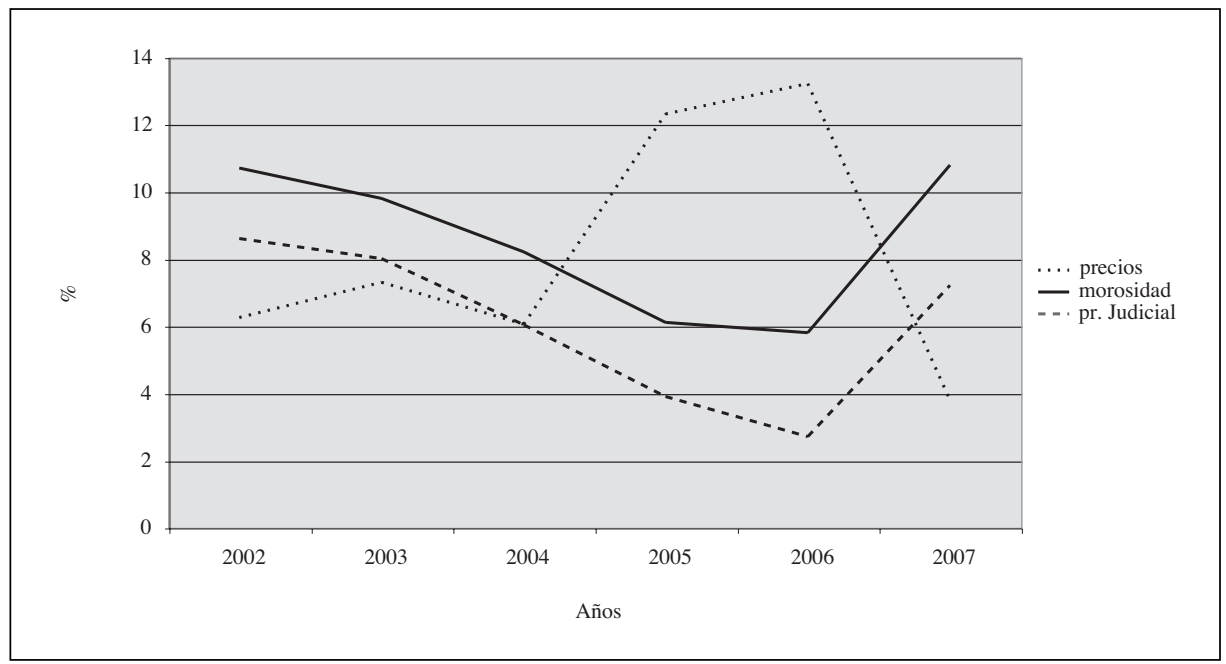

Puesto que los tipos de interés son sensiblemente más elevados que en otros tipos de hipotecas, algunas entidades del mercado subprime empezaron a promocionar hipotecas que ofrecían como atractivo una reducción de un uno por ciento en el tipo de interés durante los tres primeros años, además se amplió el número de hipotecas que permitían durante ese período sólo pagar intereses, se eliminaron en muchos casos los pagos iniciales, de modo que en muchos casos el valor de la hipoteca era igual al de la vivienda o mayor si se conseguía que algún tasador le pusiera un precio más elevado que el del mercado al objeto de poder añadir al préstamo hipotecario otros créditos al consumo o deudas asociadas con las tarjetas de crédito. En algunos casos, los agentes inmobiliarios del mercado subprime llegaron a ingresar dinero en las cuentas bancarias de sus clientes para que éstos pudieran obtener un crédito que les ayudara a pagar los intereses de los primeros años. Pero, el caso más extremo de práctica hipotecaria heterodoxa se da en aquellas hipotecas que, como en las tarjetas de crédito llamadas revolving el cliente decide cuál es el porcentaje que mensualmente quiere pagar de su deuda a partir de un determinado mínimo. Cualquier persona con unos mínimos conocimientos de finanzas sabe que si se elige el porcentaje mínimo los intereses que se pagan hasta la amortización total de un determinado saldo son elevadísimos. Pero, en el mercado hipotecario si el tipo de interés es variable y sube, esta forma de pago tiene un inconveniente adicional que puede dar lugar incluso a un aumento de la parte del principal pendiente de amortizar. 
Ahora bien, todas estas prácticas consistentes en rebajar y/o facilitar el pago de las cuotas mensuales de las hipotecas en los primeros años de la vida del préstamo necesitan financiación. En el caso contrario, la posibilidad para una entidad del mercado subprime de aumentar la cuota de mercado es nula. La financiación ya se ha visto llegó de los llamados bancos de inversión que compraron masivamente estas hipotecas y cuando creyeron excesivo el riesgo que habían asumido las titulizaron a través de los CDO.

En este proceso de financiación de las entidades que se dedicaban al mercado subprime confluyen diversos elementos: aumento del precio de la vivienda, una situación económica próspera que crea continuamente nuevos empleos, una estructura demográfica afectada por la inmigración que predice incrementos futuros en la demanda de vivienda, modificaciones en la forma de las hipotecas que proporcionan cada vez productos más asequibles en los períodos iniciales, pero también otros elementos que acaban de explicar la masiva titulización de las hipotecas del mercado subprime, en la medida que ofrecen un diferencial respecto al rendimiento de los activos libres de riesgo que es muy superior al de la deuda corporativa.

En este sentido, el diferencial incorporado en las hipotecas subprime es enormemente atractivo, especialmente cuando se le compara con el diferencial que ofrecen los bonos corporativos, para la constitución de productos financieros estructurados como los CDO. Este atractivo, además aumenta si las agencias de calificación acaban otorgando una A al conjunto del producto estructurado.

El papel jugado por las agencias de calificación ha sido muy criticado. Es obvio que muchas de las calificaciones que pusieron no se correspondían a la realidad y que los precios del riesgo fueron mal calculados. La justificación que se da es que las tasas de morosidad o de procedimientos judiciales en el momento de calificar a los CDO eran como hemos visto muy bajas. Pero así y todo había evidencias que mostraban su peligrosidad, y la ampliación repentina del mercado tenía que hacer pensar que podría darse un caso de selección adversa tal como parece que se ha producido. Como se indica en el informe del Joint Center for Housing Studies de este año, «Utilizar el porcentaje de préstamos con problemas en un momento dado del tiempo, sin embargo, enmascara el frecuentemente mayor porcentaje, en la tasa de insolvencias acumulada sobre un conjunto de préstamos unos años más tarde de cuando se originaron. A título de ejemplo, el porcentaje de préstamos del mercado subprime que se concedieron en 2000 y que habían acabado en un proceso de embargo de la vivienda hipotecada en mayo de 2005 era un preocupante 12,9 por ciento - sobre todo teniendo en cuenta que había muchas menos hipotecas basadas en las fórmulas de pagos iniciales bajos y que estos préstamos se habían beneficiado de las reducciones en los 
tipos de interés entre 2000 y 2003 y del aumento del precio de las viviendas desde el año 2000. (págs. 17-18)».

En cualquier caso, en el 2006 se vieron ya claramente los efectos de la expansión del mercado subprime. Además del efecto provocado por la subida del tipo de interés, las familias empezaron a percibir las consecuencias del tipo de hipotecas que habían contratado; las ventajas de las fórmulas de tipos iniciales bajos y con descuentos desaparecieron y los costes mensuales de las hipotecas aumentaron sustancialmente. La existencia de más de medio millón de casas sin vender, además provocó el fin de la escalada de precios, eliminando incentivos para mantenerse al día en los pagos. Esto combinado con lo anterior hizo que muchas familias no pudieron soportar la carga de las deudas adquiridas, convirtiéndose en morosos lo que ha hecho aumentar sensiblemente el número de viviendas puestas en subasta con el consiguiente efecto sobre la oferta de viviendas y los precios.

Hacia finales del año 2006, la tasa de morosidad en el mercado subprime alcanzó el 7\%. Pero esta cifra ha ido aumentando progresivamente a lo largo de 2007, hasta situarse en el mes de agosto en el 18\%. Esto ha provocado la rebaja en la calificación de muchas rodajas de los CDO y que los precios del riesgo se reajustaran rápidamente para reflejar la nueva realidad. El Markit ABX Index referido a títulizaciones de hipotecas del mercado subprime realizadas en el segundo semestre del año 2006, por ejemplo, ha pasado de 82 a 38 entre febrero y julio de 2007, reflejando la importante minusvaloración que tenía el precio del riesgo antes de que en el mes de agosto los mercados financieros entraran en una importante crisis de liquidez que ha obligado a intervenir de manera decidida a los bancos centrales para evitar una paralización absoluta de los mercados crediticios y limitar los efectos de esta crisis sobre los mercados reales.

\section{Conclusiones}

En este trabajo hemos analizado los derivados crediticios y cómo los CDO han contribuido a transferir los riesgos generados en el mercado de las hipotecas subprime al resto de mercados financieros, generando una crisis crediticia cuya magnitud por ahora es difícil precisar. En cualquier caso, las crisis acaban pasando y pueden aportar elementos positivos en la medida que contribuyen a disciplinar los mercados y ayuden a tomar decisiones más sensatas.

De todos modos, la etapa del crédito barato ha quedado atrás y este reajuste en el precio del riesgo va a tener consecuencias que se irán observando paulatinamente. En 
el origen de esta crisis está posiblemente una política monetaria que ha sido excesivamente acomodaticia y que ha alimentado un crecimiento desorbitado en los precios de la vivienda. Las nuevas fórmulas del crédito hipotecario se han adaptado a esta evolución contribuyendo de esa manera a propagar la tendencia creciente de los precios más allá de unos límites sostenibles. En la medida que los precios de la vivienda se ajustan a las condiciones del mercado hipotecario (¿cuál es la máxima proporción de renta que mensualmente se puede pagar con independencia del número de años que esto dure?) una reversión en las condiciones que se conceden las hipotecas hacia parámetros más estrictos en relación con los credit scores va a obligar a los precios de la vivienda a ajustarse a la nueva situación de los mercados hipotecarios. El efecto final sobre los precios puede ser importante, especialmente si la titulización se ve afectada para todo el conjunto de hipotecas que conceden las entidades financieras. La titulización en el pasado ha jugado un papel muy relevante para el acceso de los hogares a la posesión de una vivienda. Una disminución de sus volúmenes, por consiguiente, va a disminuir esa accesibilidad hasta que los precios disminuyan de tal manera que las entidades financieras puedan conceder de nuevo hipotecas que minimicen la probabilidad de insolvencia. Este ajuste, que puede resultar doloroso en una primera etapa es preferible a una política monetaria expansiva que vuelva a inundar los mercados de liquidez. Esto también es bueno para los productos estructurados que hemos analizado en este trabajo, en el sentido de que ayuda a mejorar la calidad de los subyacentes utilizados, permitiéndoles cumplir adecuadamente con la función para la que fueron creados. 